\title{
THE ASSESSMENT OF THE ATOPIC CHILDREN - PANEL TESTS
}

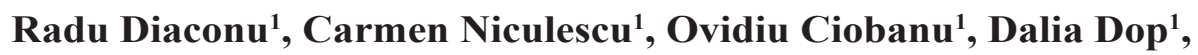 \\ Loredana Selaru ${ }^{2}$, Ligia Stanescu ${ }^{1}$ \\ ${ }^{1}$ Department "Mother and Child", University of Medicine and Pharmacy, Craiova \\ ${ }^{2}$ Emergency Clinical Hospital, Craiova
}

\begin{abstract}
The diagnosis in pediatric allergies is still a challenge, due to the age particularities and the increasing incidence. Objectives. The evaluation of the panel investigations as a diagnostic tool in children allergies. We enrolled children admitted in the Department of Pediatrics of the "Filantropia" Clinical Municipal Hospital, Craiova. We used also a control group without known history of atopy.

Results. The results showed sensitizations to pneumallergens (mostly Dermatophagoides group) associated to asthma. The food allergies were identified in a few cases without correlation to the clinical findings.
\end{abstract}

Keywords: children, allergy, atopic panel

\section{INTRODUCTION}

We are living an "allergic age" connected also to the pediatric population, interfering to multiple organs and inducing various diseases. Asthma, allergic rhinitis or food allergies are all present in children, and the incidence is raising. The health and social burden of these diseases is growing higher and higher, so one of the most important goals is establishing a precise and early diagnosis $(1,2)$.

The standard atopy testing is based on two complementary methods:

a. The skin testing (prick test, scratch test), first used in terms of chronology, is cheap, easy to perform and the results are obtained in several minutes;

b. The blood test - based mostly on specific Ig E antibodies are costly and difficult to configure. The advantages are: there are no disease limitations (they can be performed even in severe cases of eczema, when the skin testing is forbidden) and the wash out form specific medications isn't necessary (3).

The general accepted rule states that the allergic investigations must be performed when the clinical findings are suggestive for atopic diseases. Regarding the food allergies, the history recorded from the patient and/or relatives is paramount. On the other hand, the respiratory allergy testing is performed in severe or uncertain cases (4). There are a great variety of allergens, so performing specific IgE tests for all of them is difficult and costly. The age is not a limitation, the tests may be performed even in infants (5). Thus, the allergens were gathered in clusters (the panels) which consist in a standard package (respiratory or food allergens or both). The researchers reported a good sensibility, but a poor specificity $(4,6)$, although they are superior to the global IgE count. The general recommendation is to use a validated method in performing the test to ensure a maximum efficiency (7).

The main objective of our research was to study the utility of atopic panels in the diagnosis and management of specific diseases in children from Oltenia Region. The atopic panels (Fig. 1) are widely used today because all the medical specialists involved in treating children may prescribe them (pediatricians, allergologists, pulmonologists, and ENT specialists). The skin tests are - at least in our country - prescribed only by the allergologists.

\section{METHODS}

We performed a retrospective study regarding the children admitted for atopic diseases to our Pe-

Corresponding author:

Radu Diaconu, Pediatric clinic, "Filantropia” Municipal Hospital,107 Corneliu Coposu Street, Craiova

E-mail: raduteodiaconu@yahoo.com 
diatric Clinic. There are different types of panels available, so we used only a single type (the most used one) to obtain a good reproductibility. The study lasted 2 years (2013-2014). The statistical analysis was done using MSOFFICE and EPIINFO (a freeware program provided by $\mathrm{CDC}-\mathrm{Center}$ for Disease Control, USA).

We included the children suffering for atopic diseases (asthma, allergic rhinitis, atopic dermatitis, food allergies). The study group was compared to a smaller group without known history of atopic diseases.

\section{RESULTS}

The study group consisted of 152 cases (84 boys) suffering from: asthma (associated or not with another atopic disease); atopic dermatitis (31 cases); food allergies (16 cases), allergic rhinitis (without asthma) (3 cases). The comparison was made with 40 children without clinical or anamnestic evidence of atopy (Table 1).

54 patients from the study group had positive results for at least one of the components of the atopic panel vs. 5 cases in the control group: $\mathrm{p}=$ 0.02 (chi-square), $\mathrm{OR}=2.74(1.03-8.46)$ (odds ratio, confidence interval $95 \%)$.

TABLE 1. Group structure

\begin{tabular}{|l|c|c|}
\hline & $\begin{array}{c}\text { Study group } \\
(\mathbf{n}=\mathbf{1 5 2})\end{array}$ & $\begin{array}{c}\text { Control group } \\
(\mathbf{n}=\mathbf{4 0})\end{array}$ \\
\hline Boys: girls, no. & $81: 71$ & $23: 17$ \\
\hline $\begin{array}{l}\text { Mean age (yrs), standard } \\
\text { deviation }\end{array}$ & $5.2 ; 3.41$ & $5.6 ; 3.09$ \\
\hline Urban/rural, no. & $86 / 66$ & $22 / 18$ \\
\hline $\begin{array}{l}\text { Panel positive children bellow } \\
6 \text { yrs, no. }\end{array}$ & 27 & 2 \\
\hline $\begin{array}{l}\text { Panel positive children over } \\
6 \text { yrs, no }\end{array}$ & 27 & 3 \\
\hline
\end{tabular}

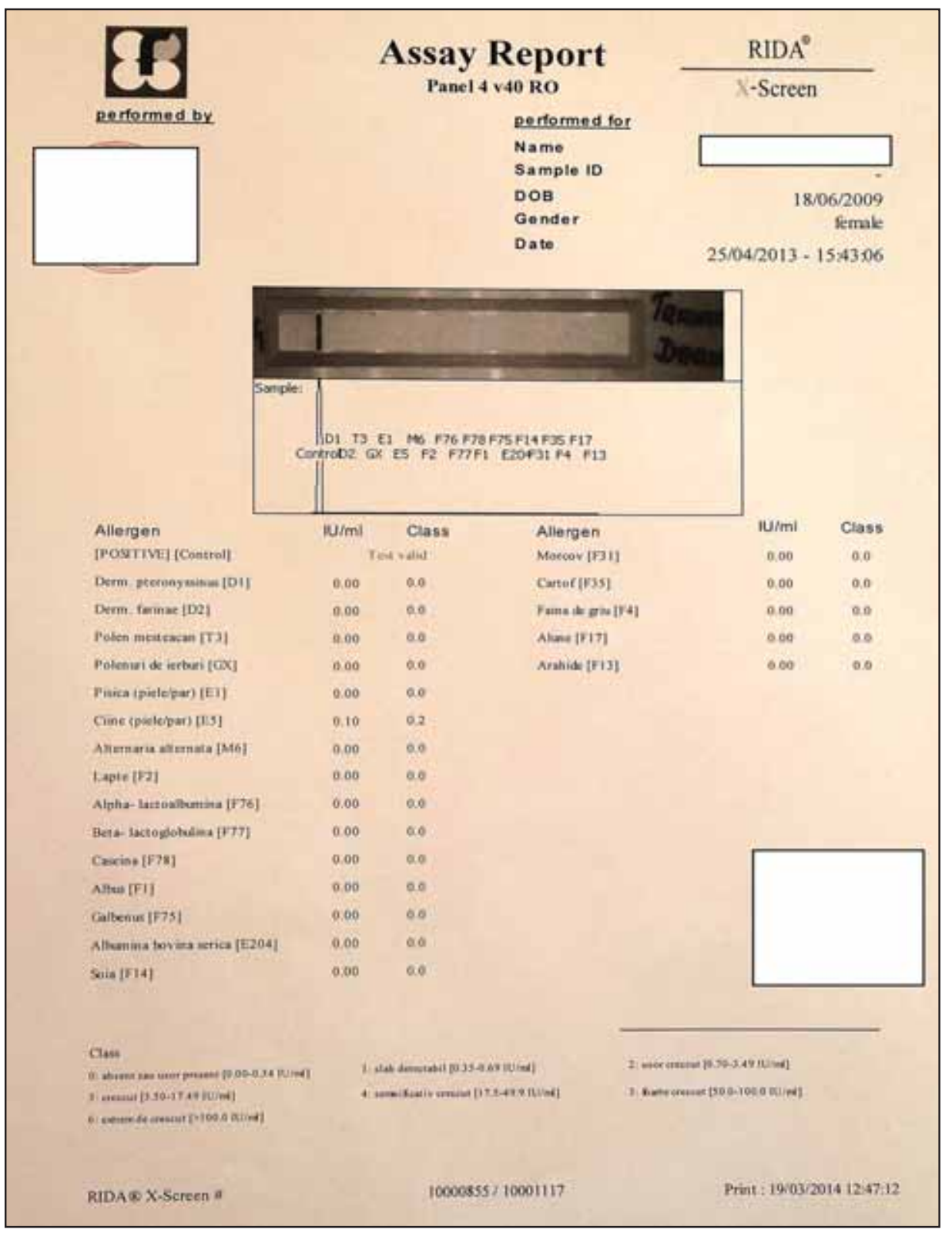


The majority of children from the study group originated from urban areas - this is the profile of our admitted children. We had no statistical significant differences regarding the urban vs. rural areas. 65 male patients had positive panel results vs. 59 females - without statistical significance.

The results recorded for the atopic children showed positive values mostly for aeroallergens, regardless the age (bellow or over 6).

TABLE 2. The results of our panels - stratified by components

\begin{tabular}{|l|c|c|}
\hline Allergen type (boys/girs), no. & $\begin{array}{c}\text { Study group } \\
(\mathbf{n}=\mathbf{1 5 2})\end{array}$ & $\begin{array}{c}\text { Control group } \\
\text { (n = 40) }\end{array}$ \\
\hline D. pteronisius & $10 / 9$ & $2 / 0$ \\
\hline D. farinae & $8 / 6$ & $3 / 1$ \\
\hline Grass polen & $4 / 3$ & $0 / 0$ \\
\hline Cat & $2 / 5$ & $0 / 2$ \\
\hline Dog & $5 / 6$ & $1 / 0$ \\
\hline Alternaria alternata & $6 / 5$ & $0 / 0$ \\
\hline Mlk & $5 / 5$ & $0 / 0$ \\
\hline Alfa-lactoglobulin & $6 / 9$ & $0 / 0$ \\
\hline Casein & $1 / 3$ & $1 / 0$ \\
\hline Egg white & $3 / 3$ & $0 / 1$ \\
\hline Egg yolk & $1 / 0$ & $0 / 0$ \\
\hline Cow albumin & $1 / 2$ & $0 / 0$ \\
\hline Soy & $1 / 0$ & $0 / 0$ \\
\hline Carrot & $1 / 0$ & $0 / 1$ \\
\hline Potato & $1 / 0$ & $0 / 1$ \\
\hline Wheat & $1 / 0$ & $0 / 0$ \\
\hline Hazelnuts & $1 / 2$ & $0 / 0$ \\
\hline Peanuts & $1 / 1$ & $2 / 0$ \\
\hline
\end{tabular}

Most of the positive pneumallergen tests were related to house dander (Dermatophagoides - the two types), followed by Alternaria and dog dander. The food allergy were reported in fewer cases. The most semnificative were: alfa - lactoglobulin (15 cases) and milk (10 cases) (Table 2). Other foods were sporadic involved in our research.

Regarding the control group, we also found 6 cases positive for house dander, all other allergens discovered scarce.

The asthma group was the most important and this group also has the most positive panels (Chart 1).

The asthma group had 43 positive cases vs. 7 cases in children suffering from atopic dermatitis $\mathrm{p}=0.02 ; \mathrm{OR}=2.48(1-6.71) ; 3$ cases in children were diagnosed with food allergies $\mathrm{p}=0.06$ (Fisher exact test) and one case was in the allergic rhinitis group.

$42 \%$ of the asthma children had positive panels (the higher rate compared to other diseases in the study group). Most of the cases were related to pneumallergens (only 4 cases were strictly food allergies) - these results are foreseeable for asthma. The atopic dermatitis cases had a lower rate of positivity, distributed evenly between aero- and food allergens.

Also, a lower rate of positive panels was recorded in food allergy and allergic rhinitis cases. Regarding the food allergy, we identified 3 positive panels, but only one of them was confirmed by clinical and anamnestic data (the oral food chal-

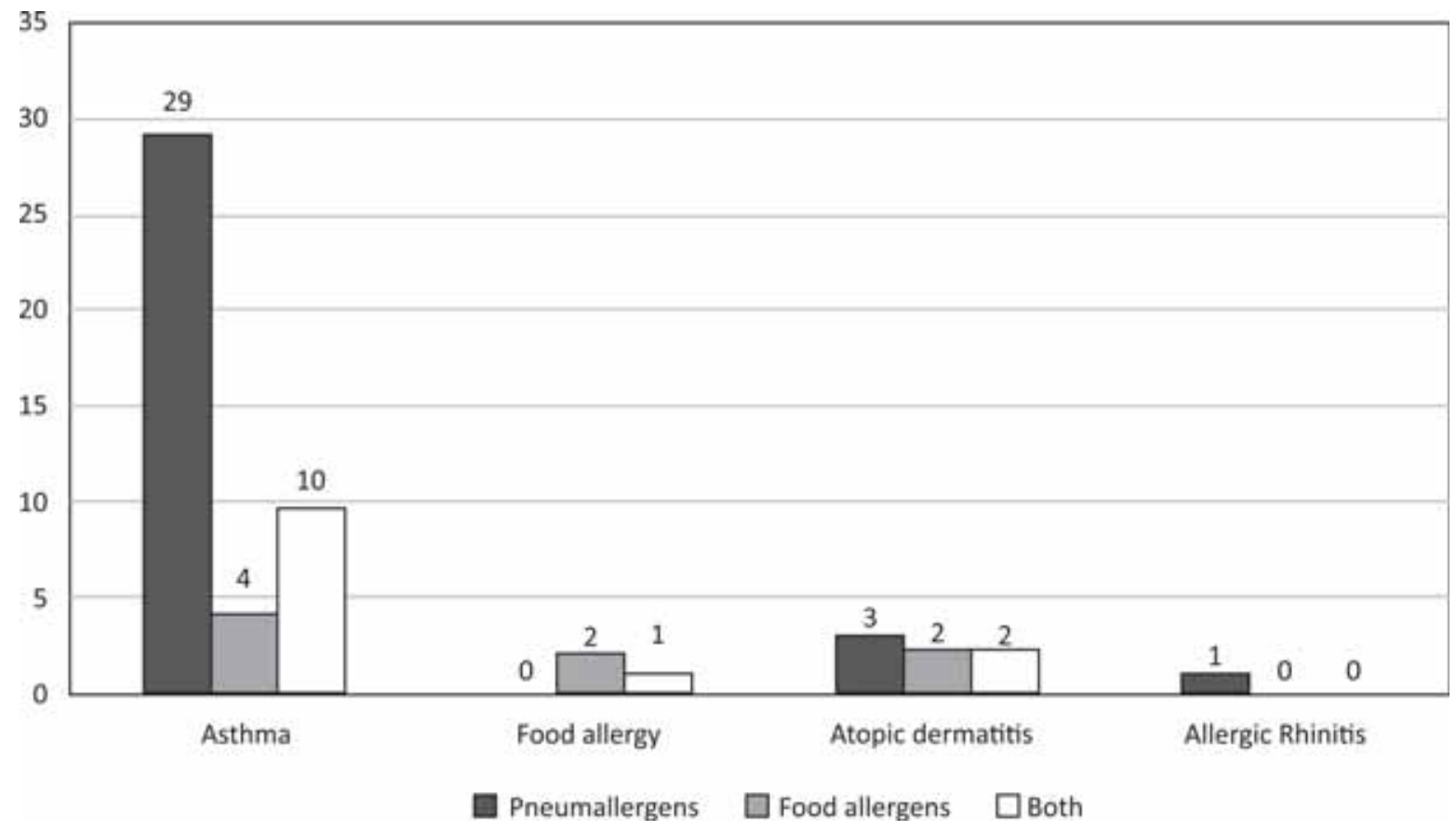

CHART 1. Results stratified by atopic disease 
lenge test). The numerical data are small, so we are not able to perform a proper statistical analysis.

Our study for aeroallergens showed positive results mostly for Dermatophagoides farinae and pteronyssinus (house dust mites), which are specific for our country. These dust mites may explain the higher prevalence of atopic diseases in Romania, but the geographic variance is still on debate (8-11). Alternaria was reported also in many cases in our study group. This fungus is responsible of the most frequent allergic reactions in humans (12), although the most frequent is Cladosporium.

The pet allergies diagnosed in our study group were mostly dog related (this is the most common pet encountered in Romanian houses). The triggers are hair, dander, urine and saliva. The same triggers are also important regarding the cat allergies (7 cases), which were rare in our children, but the atopic sensitization is stronger in these cases, compared to the dog exposure. One of the typical features in pediatrics is the controversy related to the extent of pet allergens in atopic diseases in children (13-15). There are many studies for 2 or 3 decades, but the results are equivocal.

The grass pollen was also identified in our panels. It is the second important pollen regarding the

\section{REFERENCES}

1. Dyer A.A., Gupta R., Epidemiology of childhood food allergy, Pediatr Ann. 2013 Jun 1; 42(6):91-5

2. Gupta R., Holdford D., Bilaver L., Dyer A, Holl J.L., Meltzer D. The economic impact of childhood food allergy in the United States. JAMA Pediatr. 2013 Nov; 167(11):1026-31.

3. Sicherer S.H., Wood R.A. American Academy of Pediatrics Section on Allergy and Immunology. Allergy testing in childhood: using allergen-specific lgE tests. Pediatrics. 2012; 129:193-197.

4. Bernstein I.L., Li J.T., Bernstein D.I., et al. Allergy diagnostic testing: an updated practice parameter. Ann Allergy Asthma Immunol. 2008; 100(3 suppl 3):S1-S148.

5. Cox L. Overview of serological-specific $\operatorname{lgE}$ antibody testing in children. Curr Allergy Asthma Rep 2011: 11: 447-53.

6. Eckman J., Saini S.S., Hamilton R.G. Diagnostic evaluation of food-relatedallergic diseases. Allergy Asthma Clin Immunol 2009: 5: 2.

7. Hamilton R.G., Williams P.B. Human IgE antibody serology: a primer for the practicing North American allergist/immunologist. J Allergy Clin Immunol 2010: 126: 33-8.

8. Thomas W.R. Geography of house dust mite allergens. Asian Pac J Allergy Immunol. 2010 Dec; 28(4):211-24.

9. Heinzerling L.M., Burbach G.J., Edenharter G., Bachert C., Bindslev-Jensen C., Bonini S., et al. GA(2)LEN skin test study I: atopic sensitization. The most important component is Ambrosia, described initially in Transylvania. The ragweed allergy gained more momentum as the perennial plant spread through our country. Most of our children originated from Oltenia Region and ragweed is also reported here.

\section{CONCLUSIONS}

The results were negative for most of the atopic children included in our research. The infectious (mainly viral) causes of atopy may be an explanation, as otherwise the lower sensibility of the method used. The higher positive rate was associated with asthma, mostly aeroallergens (house dander especially). Now the panel may be helpful, because the specific avoidance measures may protect these children. The food component of the panel had less utility: the positive cases were infrequent and the correlation to clinical features nonexistent.

The atopic panels are one of the most accessible methods in basic alergological research. They can be used by all the specialists involved in child care, but the results must be endorsed by other investigations, patients' history and clinical data.

GA(2)LEN harmonization of skin prick testing: novel sensitization patterns for inhalant allergens in Europe. Allergy. 2009; 64:1498-506

10. Arbes S.J. Jr, Gergen P.J., Elliott L., Zeldin D.C. Prevalences of positive skin test responses to 10 common allergens in the US population: results from the third National Health and Nutrition Examination Survey. J Allergy Clin Immunol. 2005; 116: 377-83.

11. Leung R., Ho P. Asthma, allergy, and atopy in three south-east Asian populations. Thorax. 1994; 49: 1205-10

12. Sharpe R.A., Bearman N., Thornton C.R., Husk K., Osborne N.J. Indoor fungal diversity and asthma: a meta-analysis and systematic review of risk factors. J Allergy Clin Immunol. 2015 Jan; 135(1):110-22.

13. Fretzayas A., Kotzia D., Moustaki M. Controversial role of pets in the development of atopy in children. World J Pediatr. 2013 May; $9(2): 112-9$.

14. Lodge C.J., Lowe A.J., Gurrin L.C., Matheson M.C., Balloch A., Axelrad C., Hill D.J., Hosking C.S., Rodrigues S., Svanes C., Abramson M.J., Allen K.J., Dharmage S.C. Pets at birth do not increase allergic disease in at-risk children. Clin Exp Allergy. 2012 Sep; 42(9):1377-85.

15. Simpson A., Custovic A. Early pet exposure: friend or foe? Curr Opin Allergy Clin Immunol. 2003 Feb; 3(1):7-14. 